\title{
Glutamatergic neurotransmission modulates hypoxia-induced hyperventilation but not anapyrexia
}

P.M. de Paula ${ }^{1}$ and L.G.S. Branco ${ }^{2}$

\author{
${ }^{1}$ Departamento de Ciências Biológicas, Faculdade de Medicina do Triângulo Mineiro, \\ Uberaba, MG, Brasil \\ ${ }^{2}$ Departamento de Morfologia, Estomatologia e Fisiologia, Faculdade de Odontologia \\ de Ribeirão Preto, Universidade de São Paulo, Ribeirão Preto, SP, Brasil
}

\section{Correspondence \\ P.M. de Paula \\ Departamento de Morfologia, \\ Estomatologia e Fisiologia \\ FORP, USP \\ 14040-904 Ribeirão Preto, SP \\ Brasil \\ Fax: +55-16-633-0999 \\ E-mail: depaula@uthscsa.edu}

Research supported by FAPESP, CNPq and PRONEX. P.M. de Paula was the recipient of a FAPESP postdoctoral fellowship (No. 01/06376-5).

Received February 27, 2004 Accepted August 12, 2004

\begin{abstract}
The interaction between pulmonary ventilation $\left(\mathrm{V}_{\mathrm{E}}\right)$ and body temperature $(\mathrm{Tb})$ is essential for $\mathrm{O}_{2}$ delivery to match metabolic rate under varying states of metabolic demand. Hypoxia causes hyperventilation and anapyrexia (a regulated drop in $\mathrm{Tb}$ ), but the neurotransmitters responsible for this interaction are not well known. Since L-glutamate is released centrally in response to peripheral chemoreceptor stimulation and glutamatergic receptors are spread in the central nervous system we tested the hypothesis that central L-glutamate mediates the ventilatory and thermal responses to hypoxia. We measured $\mathrm{V}_{\mathrm{E}}$ and $\mathrm{Tb}$ in 40 adult male Wistar rats ( 270 to $300 \mathrm{~g}$ ) before and after intracerebroventricular injection of kynurenic acid (KYN, an ionotropic glutamatergic receptor antagonist), $\alpha$-methyl-4-carboxyphenylglycine (MCPG, a metabotropic glutamatergic receptor antagonist) or vehicle (saline), followed by a 1-h period of hypoxia $\left(7 \%\right.$ inspired $\mathrm{O}_{2}$ ) or normoxia (humidified room air). Under normoxia, $\mathrm{KYN}(\mathrm{N}=5)$ or MCPG $(\mathrm{N}=8)$ treatment did not affect $\mathrm{V}_{\mathrm{E}}$ or Tb compared to saline $(\mathrm{N}=6)$. KYN and MCPG injection caused a decrease in hypoxiainduced hyperventilation $(595 \pm 49$ for KYN, N $=7$ and $525 \pm 84 \mathrm{ml}$ $\mathrm{kg}^{-1} \mathrm{~min}^{-1}$ for MCPG, $\mathrm{N}=6$; $\mathrm{P}<0.05$ ) but did not affect anapyrexia $\left(35.3 \pm 0.2\right.$ for $\mathrm{KYN}$ and $34.7 \pm 0.4^{\circ} \mathrm{C}$ for $\left.\mathrm{MCPG}\right)$ compared to saline $\left(912 \pm 110 \mathrm{ml} \mathrm{kg}^{-1} \mathrm{~min}^{-1}\right.$ and $\left.34.8 \pm 0.2^{\circ} \mathrm{C}, \mathrm{N}=8\right)$. We conclude that glutamatergic receptors are involved in hypoxic hyperventilation but do not affect anapyrexia, indicating that L-glutamate is not a common mediator of this interaction.
\end{abstract}

\section{Introduction}

It is well known that oxygen is crucial for ATP synthesis, cell function and consequently survival of all aerobic organisms. Respiratory, thermal and metabolic adjustments have been reported to attenuate the reduction in
Key words

- Kynurenic acid

- $\alpha$-Methyl-4-carboxyphenyl-

glycine (MCPG)

- Hypoxia

- Ventilation

- Body temperature

....................
$\mathrm{O}_{2}$ supply during exposure to hypoxia (for a review, see Ref. 1). At first sight, these responses appear to occur in opposite directions, i.e., increases in ventilatory drive and decreases in body temperature ( $\mathrm{Tb}$ ) and metabolism (2). However, this apparent contradiction may reflect the complexity of the still 
unknown mechanisms and neuromodulators involved in these responses.

Stimulation of peripheral chemoreceptors during hypoxia is associated with release of the excitatory neurotransmitter Lglutamate in several brain areas associated with pulmonary ventilation $\left(\mathrm{V}_{\mathrm{E}}\right)$. Accordingly, chemodenervation or inhibition of Lglutamate receptors nearly abolishes the hyperventilatory response to hypoxia (3). However, no reports are available about the role of L-glutamate in the mediation of hypoxic anapyrexia even though several studies have shown that L-glutamate may be involved in thermoregulation (4-6). Therefore, it is reasonable that central L-glutamate may play a role in the ventilatory and thermoregulatory responses to hypoxia, mediating this interaction.

In view of these considerations, we administered intracerebroventricularly (icv) an ionotropic (kynurenic acid) or metabotropic ( $\alpha$-methyl-4-carboxyphenylglycine, MCPG) non-selective glutamatergic antagonist and measured $\mathrm{V}_{\mathrm{E}}$ and $\mathrm{Tb}$ under normoxic and hypoxic conditions.

\section{Material and Methods}

\section{Animals}

Experiments were performed on awake adult male Wistar rats weighing 270 to 300 $\mathrm{g}$, housed at controlled temperature (25 \pm $1^{\circ} \mathrm{C}$ ) and exposed to a daily 12-h light-dark cycle, with free access to water and food. Animal care was provided in compliance with the guidelines set by the American Physiological Society (7). The rats used in this study were divided into six major groups: 1) $i c v$ kynurenic acid injection $(\mathrm{N}=5), 2) i c v$ MCPG injection $(\mathrm{N}=8)$, and 3 ) icv vehicle (saline) injection $(\mathrm{N}=6)$ in rats exposed to normoxia; 4) icv kynurenic acid injection ( $\mathrm{N}$ =7), 5) icv MCPG injection ( $\mathrm{N}=6)$, and 6) $i c v$ vehicle injection $(\mathrm{N}=8)$ in rats exposed to hypoxia.
Surgery

Animals were submitted to general anesthesia by intraperitoneal administration of $250 \mathrm{mg} / \mathrm{kg}$ 2,2,2-tribromoethanol (Aldrich, Milwaukee, WI, USA). Rats of the kynurenic acid, MCPG and vehicle groups were fixed in a stereotaxic frame and implanted with a stainless steel guide cannula $(0.7 \mathrm{~mm}, \mathrm{OD})$ into the third ventricle (coordinates: anterior $-0.4 \mathrm{~mm}$, lateral $0 \mathrm{~mm}$, dorsal 7.8-8.5 mm) for $i c v$ administration (8). The displacement of the meniscus in a water manometer assured correct positioning of the cannula in the third ventricle. The cannula was attached to the bone with stainless steel screws and acrylic cement. A tight-fitting stylet was kept inside the guide cannula to prevent occlusion. All animals were submitted to paramedian laparotomy for the insertion of a biotelemetry capsule (model: ER 4000; MiniMitter Co. Inc., Sunriver, OR, USA) into the peritoneal cavity. The wound was then closed and the implanted capsule was used for $\mathrm{Tb}$ measurements. At the end of the surgical procedures, rats were injected intramuscularly with an antibiotic cocktail (benzylpenicillin-dihydrostreptomycin-streptomycin; $80,000 \mathrm{IU} / \mathrm{kg}$ and $33 \mathrm{mg} / \mathrm{kg}$ and $33 \mathrm{mg} / \mathrm{kg}$, respectively). The surgical procedures were performed over a period of about $40 \mathrm{~min}$. Experiments were initiated 1 week after surgery in the icv kynurenic acid, icv MCPG or vehicle groups.

\section{Determination of ventilation}

Measurements of $\mathrm{V}_{\mathrm{E}}$ were performed by the body plethysmograph method $(9,10)$. Each animal was individually placed in a Plexiglas chamber ( 5 liters) connected to a reference chamber of identical size and construction. Use of the reference chamber made the system independent of minor pressure interference from the laboratory, such as those caused by opening and closing doors. During $\mathrm{V}_{\mathrm{E}}$ measurements, the flow was in- 
terrupted and the chamber sealed for short periods of time ( $\sim 2 \mathrm{~min})$. The principle is the following: the animal is placed in an air-tight chamber in which the temperature differs from $\mathrm{Tb}$. The cyclic variations of temperature and water vapor partial pressure of the tidal volume $\left(\mathrm{V}_{\mathrm{T}}\right)$ produce variations of the pressure in the chamber proportional to this volume (11). This procedure was performed once during each time of $\mathrm{V}_{\mathrm{E}}$ measurement. Signals from a differential air-pressure transducer (model MP45-14-871; Validyne, Northridge, CA, USA) were connected to a differential pressure signal conditioner (Gould Instrument Systems, Inc., Valley View, OH, USA), passed through an analogto-digital converter, digitized in a microcomputer equipped with a data acquisition software (Acquire 6600; Data Acquisition System, Gould Instrument Systems, Inc.), and then analyzed with a data-analysis software (Windaq Software for Windows by Dataq Instruments, Inc., Akron, OH, USA). Calibration for volume was obtained during each experiment by injecting the animal chamber with a known amount of air $(1 \mathrm{ml})$ using a graduated syringe. Respiratory variables such as respiratory frequency $(\mathrm{fR})$ and $\mathrm{V}_{\mathrm{T}}$ were measured, the latter being calculated by the Malan formula (11):

$V_{T}=\frac{P T}{P K} \times V K \times \frac{T C}{T R} \times \frac{(P B-P C)}{(P B-P C)-\frac{T C}{T b} \times(P B-P R)}$

where PT is the pressure deflection associated with each $\mathrm{V}_{\mathrm{T}}$, $\mathrm{PK}$ is the pressure deflection associated with injection of the calibration volume (VK), TC is the air temperature in the animal chamber, PB is the barometric pressure, $\mathrm{PR}$ is the vapor pressure of water at $\mathrm{Tb}, \mathrm{PC}$ is the vapor pressure of water vapor in the animal chamber, $\mathrm{Tb}$ is the body temperature, and TR is the room temperature. $V_{E}$ was calculated by multiplying $f R$ by $V_{T}$. $\mathrm{V}_{\mathrm{E}}$ and $\mathrm{V}_{\mathrm{T}}$ are presented at the ambient barometric pressure, at $\mathrm{Tb}$, and saturated with water vapor at this temperature.

\section{Determination of body temperature}

$\mathrm{Tb}$ was measured by biotelemetry. The animal chamber was placed on the ER 4000 telemetry receiver (Mini-Mitter Co. Inc.). The output of the receiver displayed the pulse frequency of the transmitter capsule and the corresponding $\mathrm{Tb}$ on the screen of a microcomputer containing appropriate software (Vital View, version 3.1; Mini-Mitter Co. Inc.).

\section{Experimental protocols}

Measurements of $\mathrm{V}_{\mathrm{E}}$ and $\mathrm{Tb}$ were made simultaneously. Animals were exposed first to humidified room air and then to a humidified hypoxic poikilocapnic gas mixture containing $7 \% \mathrm{O}_{2}$ (AGA, Sertãozinho, SP, Brazil). Each animal was exposed to a 1-h period of hypoxia and received a single $i c v$ injection of kynurenic acid, MCPG or vehicle. Experiments were carried out randomly between 8:00 am and 1:00 pm.

Experiment 1. Effect of kynurenic acid or $M C P G$ on the ventilatory and thermoregulatory response to normoxia. Each animal was placed in an individual Plexiglas chamber (5 liters) and allowed to move about freely while the chamber was flushed with humidified air. After the animals remained calm ( 30 min), control $V_{\mathrm{E}}$ was measured and $\mathrm{Tb}$ started to be measured continuously at 5-min intervals. Subsequently, experimental rats were treated with kynurenic acid $(100 \mathrm{nmol} / 0.2 \mu \mathrm{l})$ or MCPG (200 nmol/0.2 $\mu \mathrm{l}$; Sigma, St. Louis, MO, USA) injected into the third ventricle, while the vehicle groups received the same volume of pyrogen-free sterile saline $(150 \mathrm{mM} 0.9 \% \mathrm{NaCl})$, followed by $\mathrm{V}_{\mathrm{E}}$ measurement at 10, 15, 30, $45,60,70,85,100,115$, and 130 min during normoxia (the chamber was ventilated with humidified room air).

Experiment 2. Effect of kynurenic acid or $M C P G$ on hypoxia-induced hyperventilation and anapyrexia. After the same procedures as performed in Experiment 1, experimental rats 
were treated with kynurenic acid $(100 \mathrm{nmol} /$ $0.2 \mu \mathrm{l})$ or MCPG $(200 \mathrm{nmol} / 0.2 \mu \mathrm{l})$ injected into the third ventricle, while the vehicle groups received the same volume of pyrogen-free sterile saline $(150 \mathrm{mM} 0.9 \% \mathrm{NaCl})$, followed by $\mathrm{V}_{\mathrm{E}}$ measurement 10 min later. Subsequently, a hypoxic gas mixture $\left(7 \%\right.$ inspired $\mathrm{O}_{2}$ ) was

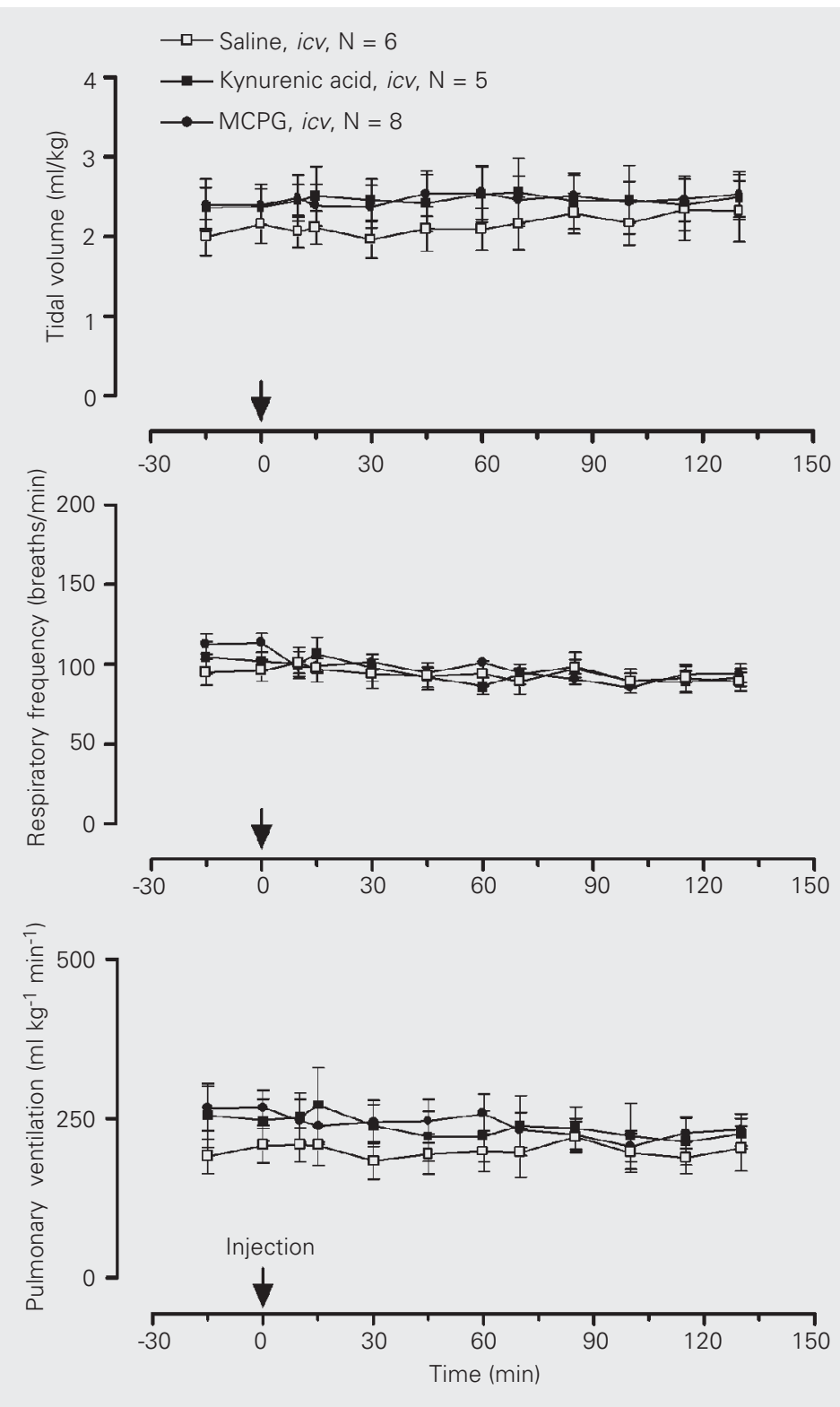

Figure 1. Effects of icv injection of kynurenic acid (100 nmol/0.2 $\mu$ l), $\alpha$-methyl-4carboxyphenylglycine (MCPG, $200 \mathrm{nmol} / 0.2 \mu \mathrm{l}$ ) or vehicle (saline) on tidal volume, respiratory frequency and pulmonary ventilation of Wistar rats exposed to normoxic conditions $\left(21 \% \mathrm{O}_{2}\right)$. The arrows indicate the time of injection. Data are reported as means \pm SEM. flushed through the chamber for $60 \mathrm{~min}$ and $\mathrm{V}_{\mathrm{E}}$ was measured at $5,20,35,50$, and $60 \mathrm{~min}$ during hypoxia. Finally, rats were returned to a 60-min period of normoxia exposure (the chamber was ventilated for 60 min with room air), and $\mathrm{V}_{\mathrm{E}}$ was measured again after 15, 30, 45, and $60 \mathrm{~min}$.

\section{Statistical analysis}

Data are reported as means \pm SEM and were analyzed statistically by repeated measures multivariate analysis of variance (MANOVA), with factors being treatment (kynurenic acid or MCPG), time and stimulus (hypoxia). In the case of significant interactions, one-way ANOVA was performed each time. The Duncan test was used for multiple comparisons. The statistical analysis was performed using the SPSS software (SPSS Inc. for Windows 6.0, Chicago, IL, USA). The level of significance was set at $\mathrm{P}$ $<0.05$.

\section{Results}

During the experiments the mean $( \pm \mathrm{SEM})$ chamber temperature was $24.0 \pm 0.5^{\circ} \mathrm{C}$ and mean room temperature was $23.0 \pm 0.7^{\circ} \mathrm{C}$. There was no statistically significant difference in $\mathrm{Tb}$ between normoxic $\left(37.1 \pm 0.1^{\circ} \mathrm{C}\right)$ and hypoxic $\left(36.8 \pm 0.1^{\circ} \mathrm{C}\right)$ animals.

\section{Experiment 1. Effects of icv injection of kynurenic acid or MCPG on resting ventila- tion and body temperature}

Under normoxic conditions, icv injection of kynurenic acid or MCPG caused no significant changes in $\mathrm{V}_{\mathrm{E}}$ (Figure 1) or $\mathrm{Tb}$ (Figure 2).

Experiment 2. Effects of icv injection of kynurenic acid and MCPG on hypoxiainduced hyperventilation and anapyrexia

Figure 3 shows the effect of $i c v$ injection of kynurenic acid and MCPG on $\mathrm{V}_{\mathrm{T}}$, fR and 

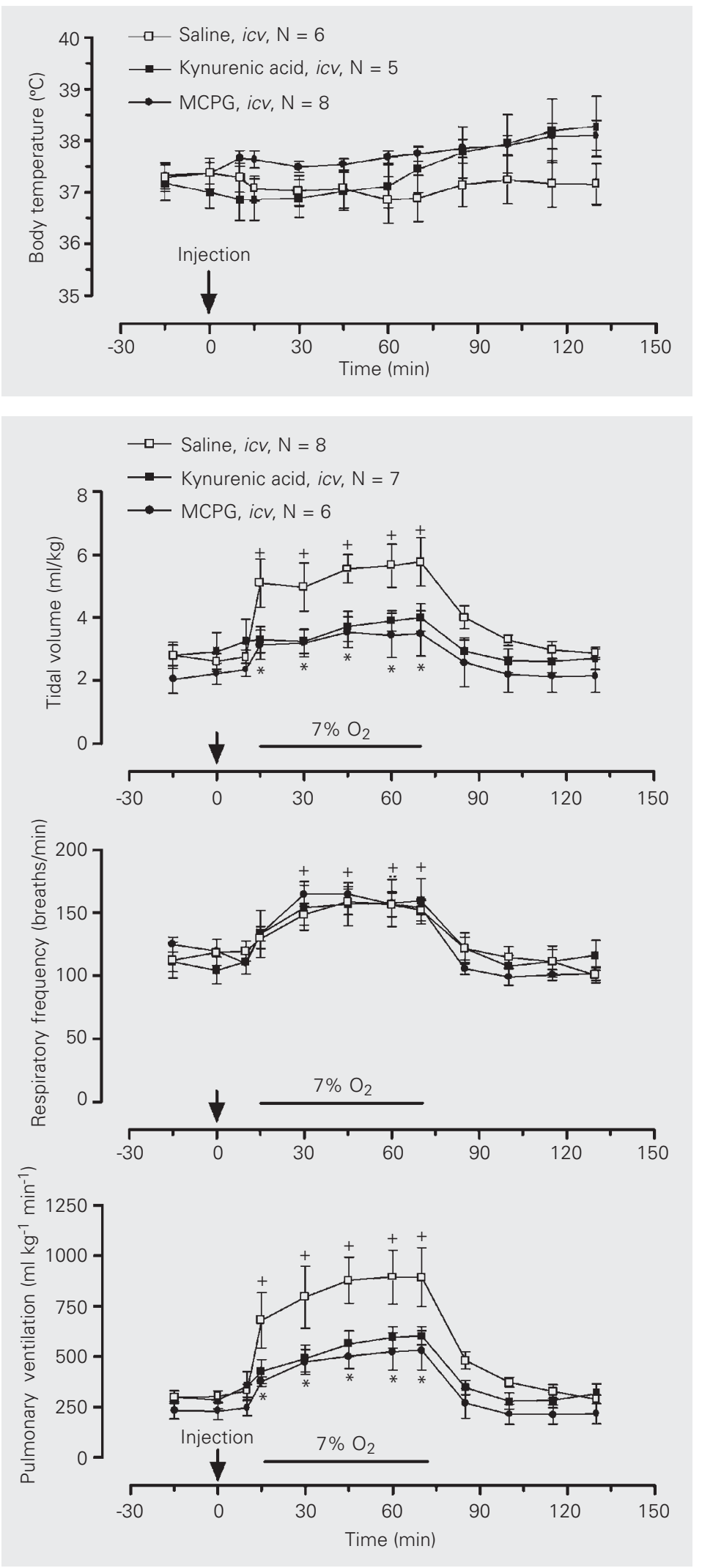

Figure 2. Effects of icv injection of kynurenic acid $(100 \mathrm{nmol} / 0.2$ $\mu \mathrm{ll}), \alpha$-methyl-4-carboxyphenylglycine (MCPG, $200 \mathrm{nmol} / 0.2 \mu \mathrm{l}$ ) or vehicle (saline) on the body temperature of rats exposed to normoxic conditions $\left(21 \% \mathrm{O}_{2}\right)$. The arrow indicates the time of injection. Data are reported as means \pm SEM

Figure 3. Effects of icv injection of kynurenic acid $(100 \mathrm{nmol} / 0.2$ $\mu \mathrm{ll}), \alpha$-methyl-4-carboxyphenylglycine (MCPG, $200 \mathrm{nmol} / 0.2 \mu \mathrm{l}$ ) or vehicle (saline) on tidal volume $\left(V_{T}\right)$, respiratory frequency $\left(f_{R}\right)$ and pulmonary ventilation $\left(V_{E}\right)$ of rats exposed to hypoxia $\left(7 \% \mathrm{O}_{2}\right)$. +Significant increase $(P<0.05)$ in $V_{T}, f_{R}$ and $V_{E}$ during hypoxia compared to control values (time zero) (MANOVA followed by the Duncan test). ${ }^{*}$ Significant difference $(P<0.05)$ between vehicle (saline) and kynurenic acid and MCPG treatments during hypoxia (MANOVA followed by the Duncan test). The arrows indicate the time of injection. Data are reported as means \pm SEM. 
$\mathrm{V}_{\mathrm{E}}$. Typical hypoxia-induced hyperventilation (increases in $\mathrm{V}_{\mathrm{T}}$, $\mathrm{fR}$ and $\mathrm{V}_{\mathrm{E}}$ ) was observed after $i c v$ saline (vehicle) injection, whereas $i c v$ injection of kynurenic acid and MCPG reduced the ventilatory response to hypoxia, acting essentially on $\mathrm{V}_{\mathrm{T}}$.

Typical hypoxia-induced anapyrexia was observed after saline treatment. Kynurenic acid and MCPG icv injection did not affect the drop in $\mathrm{Tb}$ induced by hypoxia (Figure 4).

\section{Discussion}

The present study shows that both ionotropic and metabotropic glutamatergic receptors play an excitatory role in the ventilatory response to hypoxia but do not participate in the neural pathways that mediate hypoxia-induced anapyrexia, indicating that L-glutamate is not a common mediator of these responses.

\section{Ventilatory response to hypoxia}

Hypoxia elicits a number of compensatory responses, including increased ventilation (for a review, see Ref. 1). It is known that hyperventilation induced by hypoxia results primarily from the activation of peripheral chemoreceptors located in the aortic and carotid bodies and the subsequent processing of information by the central ner-

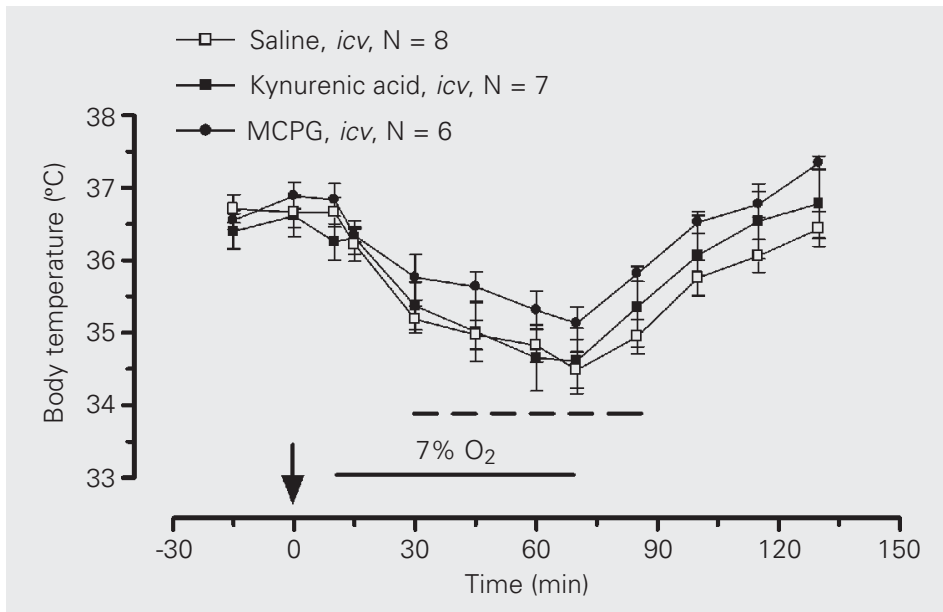

vous system (CNS; 12). Mizusawa et al. (13) demonstrated that afferent nerve fibers carrying peripheral chemoreceptor impulses to the CNS cause release of L-glutamate during hypoxia. Accordingly, inhibition of L-glutamate receptors nearly abolishes the hyperventilatory response to hypoxia $(3,13-17$, present data).

Glutamate receptors are divided into two major classes, ionotropic and metabotropic glutamatergic receptors. Ionotropic glutamatergic receptors are ligand-gated ion channels and can be antagonized by kynurenic acid (18). Metabotropic glutamatergic receptors are $\mathrm{G}$ protein-coupled receptors that modulate second messenger systems and can be antagonized by MCPG (19).

In the present study we report that $i c v$ injections of kynurenic acid or MCPG (Figure 1) have no effect on ventilation under normoxia, indicating that central L-glutamate has no role in the control of pulmonary ventilation under resting conditions. However, some studies have shown that systemic administration (20), as well as microinjection into the brain stem, of both agonists and glutamatergic antagonists produce apnea $(21,22)$. In the present study, which, to our knowledge, was the first to use icv injections of glutamatergic antagonists, this response was not observed. These differences may be explained by the use of different experimen-

Figure 4. Effects of icv injection of kynurenic acid $(100$ $\mathrm{nmol} / 0.2 \mu \mathrm{l}), \alpha$-methyl-4-carboxyphenylglycine (MCPG, $200 \mathrm{nmol} / 0.2 \mu \mathrm{l}$ ) or vehicle (saline) on hypoxia-induced anapyrexia in rats. There was no significant difference between vehicle and kynurenic acid or MCPG treatments. The dotted bar represents the period of time during which a significant reduction in body temperature was observed in comparison to the normoxic control period (time zero; $P<0.05$, MANOVA). The arrow indicates the time of injection. Data are reported as means \pm SEM. 
tal approaches, of different species (cats) and of anesthetized animals.

We also observed that $i c v$ injections of kynurenic acid or MCPG (Figure 3) reduce the ventilatory response to hypoxia, indicating that central L-glutamate plays an excitatory role during exposure to hypoxia. These findings corroborate previous reports in the literature that investigated the same question. When different glutamatergic receptor antagonists are applied directly to the ventral surface of the medulla $(14,17)$, into the nucleus tractus solitarii (13), intra-ventriculocisternally (3) or systemically $(15,16)$, a reduction in the magnitude of the hyperventilatory response to hypoxia is observed.

The effect of icv injection of kynurenic acid and MCPG on the ventilatory response to hypoxia observed in the current study resembles the effect observed after icv injection of L-NAME (a nonselective nitric oxide synthase blocker) (23). In fact, activation of brain L-glutamate has been shown to lead to synthesis and release of nitric oxide $(24,25)$ and Ogawa et al. (26) have suggested a possible interaction between L-glutamate and nitric oxide in the CNS in the control of breathing during hypoxia. In summary, our data indicate that ionotropic and metabotropic glutamatergic receptors play no role in the respiration of awake rats under resting conditions, but exert an excitatory modulation in the ventilatory response to hypoxia, acting mainly on $\mathrm{V}_{\mathrm{T}}$.

\section{Thermoregulatory response to hypoxia}

Hypoxia reduces $\mathrm{Tb}$ and metabolism in newborns and adults of many species $(27,28)$, including humans (29). Hypoxia also leads animals to select ambient temperatures that favor $\mathrm{Tb}$ below those seen in normoxia, suggesting the occurrence of a drop in the thermoregulatory set point $(30,31)$. On this basis, this $\mathrm{Tb}$ drop has been called anapyrexia, i.e., a regulated decrease in $\mathrm{Tb}(1,32)$, instead of hypothermia.
No reports are available about the role of L-glutamate in hypoxia-induced anapyrexia despite the fact that several studies have shown that L-glutamate may be involved in thermoregulation. L-glutamate receptors have been shown to participate in pyrogenic fever (5) as well as in hypothermia induced by dithiothreitol (4). Furthermore, Pechnick et al. (33) observed an increase in Tb after acute inhibition of L-glutamate receptors by $( \pm$ )-dizocilpine maleate (MK 801), an Lglutamate antagonist. Moreover, injections of L-glutamate into the dorsomedial hypothalamus reduce the thermogenic activity, while injections into the medial preoptic area lead to a biphasic response with a decrease followed by an increase in heat production (34).

In the present study, we investigated if Lglutamate influences the thermoregulatory responses to hypoxia within the CNS. Our data indicate that L-glutamate does not participate in this response (Figures 2 and 4). Interestingly, a recent study from our laboratory (6) demonstrated that icv pretreatment with kynurenic acid abolished vasopressininduced hypothermia. The reason for such differences may reside in the type of stimulus, which may trigger different mechanisms resulting in a drop in $\mathrm{Tb}$.

In addition to L-glutamate, other mediators have been recently reported to participate in the hypoxia-induced anapyrexia and/ or hyperventilation. Central dopamine affects thermal and metabolic responses to hypoxia without affecting hyperventilation (35), which is the opposite of the present results, i.e., L-glutamate affecting ventilation but not $\mathrm{Tb}$. Therefore, dopamine and Lglutamate may control each system independently. L-glutamate may act mainly in the brain stem areas associated with respiration (such as nucleus tractus solitarii and ventrolateral medulla) and dopamine may mainly act by stimulating central areas (such as the hypothalamus) involved in thermoregulation, leading to respiratory, thermal and 
metabolic adjustments during hypoxia exposure. Yet, some other modulators released during hypoxia exposure in the CNS may have effects on both respiratory and thermoregulatory systems, such as adenosine (36) and nitric oxide (23), which attenuate hypoxic hyperventilation and anapyrexia.

The present results indicate that central glutamatergic receptors do not participate in the control of $\mathrm{V}_{\mathrm{E}}$ during normoxia in awake rats, but contribute to the development and maintenance of hypoxia-induced hyperven- tilation. On the other hand, these receptors do not play a role in the mechanism responsible for hypoxic anapyrexia. Therefore, we conclude that the effect of L-glutamate within the CNS on hyperventilation is independent from anapyrexia induced by hypoxia.

\section{Acknowledgments}

We thank Daniela L. Oliveira, Mauro F. Silva and Nadir Martins Fernandes for excellent technical assistance.

\section{References}

1. Steiner AA \& Branco LGS (2002). Hypoxia-induced anapyrexia: implications and putative mediators. Annual Review of Physiology, 64: 263-288.

2. Gautier $H$ (1996). Interactions among metabolic rate, hypoxia and control of breathing. Journal of Applied Physiology, 81: 521-527.

3. Ang RC, Hoop B \& Kazemi H (1992). Role of glutamate as the central neurotransmitter in the hypoxic ventilatory response. Journal of Applied Physiology, 72: 1480-1487.

4. Canini F, Brejot T, Aleo P, Mercier S \& Bourdon L (2001). NMDA receptors are involved in dithiothreitol-induced hypothermia. European Journal of Pharmacology, 426: 179-183.

5. Huang WT, Tsai SM \& Lin MT (2001). Involvement of brain glutamate release in pyrogenic fever. Neuropharmacology, 41: 811-818.

6. Paro FM, Almeida MC, Carnio EC \& Branco LGS (2003). Role of Lglutamate in systemic AVP-induced hypothermia. Journal of Applied Physiology, 94: 271-277.

7. American Physiological Society (2002). Guiding principles for research involving animals and human beings. American Journal of Physiology, 283: R281-R283.

8. Paxinos G \& Watson C (1998). The Rat Brain in Stereotaxic Coordinates. 3rd edn. Academic Press, San Diego, CA, USA.

9. Bartlett Jr D \& Tenney SM (1970). Control of breathing in experimental anemia. Respiration Physiology, 10: 384-395.

10. Menkes HA \& DuBois AB (1969). Subtraction of cardiopneumatic pulsations from body plethysmograph. Journal of Applied Physiology, 27: 910-911.

11. Malan A (1973). Ventilation measured by body plethysmography in hibernating mammals and in poikilotherms. Respiration Physiology, 17: 32-44

12. Taylor EW, Jordan D \& Coote JH (1999). Central control of cardiovascular and respiratory systems and their interactions in vertebrates. Physiological Reviews, 79: 855-916.

13. Mizusawa A, Ogawa $H$, Kikuchi $Y$, Hida W, Kurosawa H, Okabe $S$, Takishima T \& Shirato K (1994). In vivo release of glutamate in nucleus tractus solitarii of the rat during hypoxia. Journal of Physiology, 478: 55-65

14. Kazemi H \& Hoop B (1991). Glutamic acid and gamma-aminobutyric acid neurotransmitters in central control of breathing. Journal of Applied Physiology, 70: 1-7.

15. Lin J, Suguihara C, Huang J, Hehre D, Devia C \& Bancalari E (1996).
Effect of N-methyl-D-aspartate receptor blockade on hypoxic ventilatory response in unanesthetized piglets. Journal of Applied Physiology, 80: 1759-1763.

16. Ohtake PJ, Torres JE, Gozal YM, Graff GR \& Gozal D (1998). NMDA receptors mediate peripheral chemoreceptor afferent input in the conscious rat. Journal of Applied Physiology, 84: 853-861.

17. Soto-Arape I, Burton MD \& Kazemi H (1995). Central amino acid neurotransmitters and the hypoxic ventilatory response. American Journal of Respiratory and Critical Care Medicine, 151: 1113-1120.

18. Birch PJ, Grossman CJ \& Hayes AG (1988). Kynurenate and FG9041 have both competitive and non-competitive antagonist actions at excitatory amino acid receptors. European Journal of Pharmacology, 151: 313-315.

19. Conn PJ \& Pin JP (1997). Pharmacology and functions of metabotropic glutamate receptors. Annual Review of Pharmacology and Toxicology, 37: 205-237

20. Abrahams TC, Taveira da Silva AM, Hamosh P, McManigle JE \& Gillis RA (1993). Cardiorespiratory effects produced by blockade of excitatory amino acid receptors in cats. European Journal of Pharmacology, 238: 223-233.

21. McCrimmon DR, Feldman JL \& Speck DF (1986). Respiratory motoneuronal activity is altered by injections of picomoles of glutamate into cat brain stem. Journal of Neuroscience, 6: 2384-2392.

22. McManigle JE, Panico WH, Da Silva AM \& Gillis RA (1995). Respiratory effects produced by microinjection of L-glutamate an uptake inhibitor of L-glutamate into the caudal subretrofacial area of the medulla. European Journal of Pharmacology, 280: 257-275.

23. Fabris G, Anselmo-Franci JA \& Branco LGS (1999). Role of nitric oxide in hypoxia-induced hyperventilation and hypothermia: participation of the locus coeruleus. Brazilian Journal of Medical and Biological Research, 32: 1389-1398.

24. Garthwaite J, Charles SL \& Chess-Williams R (1988). Endotheliumderived relaxing factor release on activation of NMDA receptors suggests role as intercellular messenger in the brain. Nature, 336: 385-388.

25. Garthwaite J, Garthwaite G, Palmer RM \& Moncada S (1989) NMDA receptor activation induces nitric oxide synthesis from arginine in rat brain slices. European Journal of Pharmacology, 172: 413-416.

26. Ogawa H, Mizysawa A, Kikuchi $Y$, Hida W, Miki H \& Shirato $K$ 
(1995). Nitric oxide as a retrograde messenger in the nucleus tractus solitarii of rats during hypoxia. Journal of Physiology, 486: 494504.

27. Gellhorn E (1937). Oxygen deficiency, carbon dioxide and temperature regulation. American Journal of Physiology, 120: 190-194.

28. Hill JR (1959). The oxygen consumption of newborn and adult mammals. Its dependency on the oxygen tension in the inspired air on the environmental temperature. Journal of Physiology, 149: 346373.

29. Cross KW, Tizard JPM \& Trythall DAH (1958). The gaseous metabolism of the newborn infant breathing 15\% oxygen. Acta Paediatrica, 47: 217-237.

30. Gordon CJ \& Fogelson L (1991). Comparative effects of hypoxia on behavioral thermoregulation in rats, hamsters and mice. American Journal of Physiology, 260: R120-R125.

31. Wood SC \& Stabenau EK (1998). Effect of gender on thermoregulation and survival of hypoxic rats. Clinical and Experimental Pharma- cology and Physiology, 25: 155-158

32. Branco LGS \& Malvin GM (1996). Thermoregulatory effects of cyanide and azide in toad, Bufo marinus. American Journal of Physiology, 270: R169-R173.

33. Pechnick RN, Wong CA, George R, Thurkauf A, Jacobson AE \& Rice $K C$ (1989). Comparison of the effects of the acute administration of dexoxadrol, levoxadrol, MK-801 and phencyclidine on body temperature in the rat. Neuropharmacology, 28: 829-835.

34. Yoshimatsu H, Egawa M \& Bray GA (1993). Sympathetic nerve activity after discrete hypothalamic injection of L-glutamate. Brain Research, 601: 121-128.

35. Barros RCH \& Branco LGS (2002). Central dopamine modulates anapyrexia but not hyperventilation induced by hypoxia. Journal of Applied Physiology, 92: 975-981.

36. Barros RCH \& Branco LGS (2000). Role of central adenosine in the respiratory and thermoregulatory responses to hypoxia. NeuroReport, 1: 193-197. 
